\title{
CONFERÊNCIA
}

\section{CRISE ESTRUTURAL, CONJUNTURA NACIONAL, CORONAVIRUS E EDUCAÇÃO - O DESMONTE DA EDUCAÇÃO NACIONAL}

\author{
Dermeval Saviani 1
}

\section{Introdução}

O assunto deste artigo decorre do tema do primeiro evento do Ciclo de Debates promovido pelo Grupo de Estudos e Pesquisas "História, Sociedade e Educação no Brasil" (HISTEDBR), de forma virtual, realizado no dia 5 de junho de 2020. Além do conteúdo de minha participação no referido evento, introduzo no artigo aspectos de outras participações em "lives" que vêm sendo realizadas nesse período de restrições decorrentes da pandemia do Covid 19.

Ao tratar do tema começo por considerar a crise estrutural do capitalismo, própria da época atual, considerando a emergência, na conjuntura nacional, da pandemia do coronavírus e seu impacto no funcionamento das escolas. No segundo momento trato da tendência advinda do neoliberalismo de subordinar a educação aos mecanismos de mercado que, na conjuntura da crise política brasileira, redunda num verdadeiro desmonte da educação nacional. E, no terceiro momento, apresento a perspectiva da escola unitária, exigida pelo nível atingido pelas forças produtivas, como forma de superação do desmonte da educação nacional. Por fim, à guisa de conclusão, destaco que, além da reorganização da educação nacional com base na escola unitária é necessário que os educadores se articulem com os sindicatos de trabalhadores de todas as categorias profissionais e aos movimentos sociais

\footnotetext{
1 Professor Emérito da UNICAMP, Pesquisador Emérito do CNPq e Coordenador Geral do Grupo de Estudos e Pesquisas "História, Sociedade e Educação no Brasil" (HISTEDBR). Orcid iD: http://orcid.org/0000-0002-3148-3055. E-mail: dermeval.saviani.2013@gmail.com
} 
populares na luta para implantar uma nova sociedade verdadeiramente livre e emancipada.

\section{Sobre a crise estrutural, o coronavírus e as escolas na conjuntura nacional}

Ao abordarmos a conjuntura atual, a palavra que vem à tona na tentativa de sua caracterização é crise. Daí a consideração de que estamos vivendo uma crise de grandes proporções que se manifesta como crise política, econômica, social e sanitária. Numa palavra, trata-se de uma crise geral, que diz respeito à forma social atual como um todo, ou seja, trata-se de uma crise da sociedade capitalista.

Diante dessa situação, uma primeira diferenciação a ser feita é que, tratando da conjuntura atual, devemos observar que, se a crise sanitária representada pela pandemia do Coronavírus é uma crise conjuntural, ou seja, própria do momento atual e que deve passar, permitindo a continuidade da vida humana, a crise que afeta a sociedade capitalista é de outro teor.

Com efeito, as crises são inerentes ao capitalismo. Mas as crises com as quais o capitalismo convive são crises parciais, conjunturais, relativas a determinados aspectos que podem ser controlados, sem chegar a colocar em questão a totalidade da forma social capitalista. Tais crises configuram momentos de aguçamento das contradições que movem o próprio desenvolvimento capitalista e que, ao afetar, ainda que severamente, aspectos determinados do conjunto, não chegam a ameaçar sua sobrevivência, pois o sistema dispõe de mecanismos que the permitem deslocar as contradições contornando a crise e prosseguindo em sua marcha.

Até aqui falamos de crises parciais, obviamente não estruturais. Mas convém observar que mesmo crises gerais podem não se revestir de caráter estrutural. Assim, "nos Estados Unidos da América, por exemplo, embora tenham ocorrido 35 ciclos econômicos e crises nos 150 anos decorridos de 1834 até o presente (1984), apenas duas - a Grande Depressão de 1873-1893 
e a Grande Depressão de 1929-1941 - podem ser classificadas como crises gerais" (Anwar Shaikh. In: Dicionário do Pensamento Marxista, p. 85). Embora essas crises gerais, pelo caráter mundializado do capitalismo, tenham afetado também os demais países, de modo especial no caso da segunda quando os Estados Unidos já haviam se convertido em potência mundial hegemônica, não chegaram, contudo, a se converter plenamente em crise estrutural.

Conforme Mèszáros, uma crise é estrutural quando "afeta a totalidade de um complexo social em todas as relações com suas partes constituintes ou subcomplexos, como também a outros complexos aos quais é articulada" (MÈSZÁROS, 2002, p. 797). É distinta, pois, da crise não estrutural que "afeta apenas algumas partes do complexo em questão, e assim, não importa o grau de severidade em relação às partes afetadas, não pode pôr em risco a sobrevivência da estrutura global" (idem, ibidem). E o próprio Mèszáros (idem, p. 796) considera estrutural a atual crise do capitalismo, tendo em vista o seu caráter universal, seu alcance global, sua escala de tempo contínua ou permanente e seu modo de desdobrar-se rastejante, isto é, mesmo sem negar possíveis manifestações mais espetaculares, a crise vai persistentemente se insinuando nas várias dimensões da estrutura, minandoa progressivamente.

Hoje os sinais da crise estrutural estão bem mais visíveis. Tendo se estendido por toda a Terra o capitalismo não tem mais para onde se expandir e passa a obter uma sobrevida por meio da "produção destrutiva". Isso porque aquilo que é destruído pode ser reconstruído a partir das relações sociais de produção dominantes, baseadas na propriedade privada. Mas já não é mais possível desenvolver novas forças produtivas porque as relações sociais privadas, que até meados do século XX impulsionaram o desenvolvimento das forças produtivas, a partir da crise dos anos de 1970, que determinou a reconversão produtiva com o advento do neoliberalismo, passaram a frear o avanço das forças produtivas gerando os fenômenos dos desastres ambientais, acidentes de trânsito, guerras localizadas e, mais recentemente, as manifestações acompanhadas da 
queima de veículos, quebra de lojas e outras formas destrutivas nomeadas pela imprensa como vandalismo assim como pelas ações do crime organizado tanto a partir das prisões como nas áreas de controle do tráfico de drogas e de atuação das milícias. Aliás, os dois setores que movimentam as maiores somas de capitais nos dias de hoje são o comércio de armamentos e o comércio de drogas.

Mas além desses eventos extrínsecos ao processo produtivo que alimentam a reprodução capitalista, o próprio modo de produzir incorporou intrinsecamente a forma destrutiva ao reger-se pela obsolescência programada mediante a qual os bens são produzidos para durar pouco exigindo em tempos cada vez mais curtos a necessidade de sua substituição. Isso ocorre com todos os produtos sendo mais evidente nos equipamentos eletrônicos que utilizam como matéria prima o plástico cujos artefatos obsoletos inundam o planeta danificando o meio ambiente.

Com a desintegração do "socialismo real", todos os problemas do mundo de hoje são problemas do capitalismo. Em 1990, no calor dos acontecimentos relativos ao colapso da União Soviética, escrevi que em lugar de acreditar que o socialismo morreu e que Marx fracassou, as evidências apontam em sentido contrário, realçando a consistência da tese de Marx de que "nenhum modo de produção desaparece antes de ter esgotado todas as suas possibilidades" e que não é possível uma solução parcial para os problemas do capitalismo. Portanto, o que se comprova é que a tentativa de se implantar o socialismo em apenas uma parte do mundo se revelou inviável. Mas não se pode dar como comprovada a inviabilidade do socialismo como solução global. Agora não há mais os problemas do socialismo paralelamente aos problemas do capitalismo. Todos os problemas do mundo, hoje, são problemas do capitalismo. E precisam ser resolvidos, o que só pode ocorrer com a superação do próprio capitalismo como totalidade. E a superação do capitalismo, a partir do desenvolvimento de suas contradições internas, é o que a prática histórica e a teoria dessa prática vêm explicitando por meio da categoria "socialismo". Fora disto a alternativa que resta é a barbárie da qual também já se 
manifestam diversos sinais na atual conjuntura (SAVIANI, 1991, P. 103-104). Portanto, a solução da crise global implica a transformação radical do capitalismo construindo, pela práxis revolucionária, a sociedade socialista.

Cumpre observar que, no quadro da luta de classes, mesmo as crises conjunturais são encaradas em perspectivas opostas pelas classes em confronto. Enquanto a classe dominante tende a encarar as crises como simples disfunções que apenas exigem rearranjos (reformas), a classe dominada tenderá a encarar as crises conjunturais como expressão das contradições de estrutura, buscando explorar a crise de conjuntura para mudar a correlação de forças tendo em vista a transformação estrutural da sociedade. É o que está ocorrendo com a crise sanitária que tende a ser utilizada pelos setores dominantes da sociedade para aprofundar as formas de dominação enquanto as classes dominadas constatam que se escancara a incapacidade da (des)ordem social dominante de resolver os problemas agravados pela pandemia impondo-se a necessidade de sua superação pela construção de uma nova sociedade em que a apropriação dos meios de produção e dos produtos do trabalho seja socializada em consonância com os processos de produção já socializados pelo próprio capitalismo.

O advento da pandemia do Corona vírus provocou a necessidade do isolamento social com a recomendação da permanência em casa. Em consequência, no início do período letivo de 2020 as escolas foram fechadas e as aulas suspensas. Surgiu, então, a proposta do "Ensino Remoto" para suprir a ausência das aulas. Essa expressão "ensino remoto" vem sendo usada como alternativa à Educação a Distância, pois a EaD já tem existência regulamentada coexistindo com a educação presencial como uma modalidade distinta oferecida regularmente. Então, o "ensino remoto" é posto como um substituto do ensino presencial excepcionalmente nesse período da pandemia em que a educação presencial se encontra interditada.

Como se vê, por definição, o ensino remoto não pode se equivaler ao ensino presencial, sendo admitido apenas como exceção; e se diferencia 
da Educação a Distância porque também não preenche os requisitos definidos para essa modalidade. No entanto, mesmo para funcionar como substituto do ensino presencial certas condições precisam ser preenchidas tais como:

a) o acesso de todos os alunos ao ambiente virtual propiciado pela aparelhagem representada por computadores, celulares e similares;

b) considerando que alunos e professores devam estar confinados nas suas residências, estas deverão estar todas equipadas com acesso à internet;

c) é preciso que todos os estudantes preencham os requisitos mínimos para acompanharem, com proveito, o ensino remoto. Ou seja, é preciso que todos estejam não apenas alfabetizados em sentido estrito, mas também em sentido funcional e, mais do que isso, não sejam analfabetos digitais.

Ora, está evidenciado que essas condições não são preenchidas para a grade maioria dos alunos e, mesmo, para boa parte dos professores. E, mesmo assim, diversas redes públicas de ensino e instituições de ensino superior vêm lançando mão do ensino remoto para cumprir o calendário escolar. E grande parte das instituições privadas estão aproveitando a pandemia para ampliar o recurso a procedimentos próprios da EaD e promovendo demissões em larga escala como aconteceu com a Uninove que em 22 de junho demitiu 300 professores por meio de um simples comunicado na internet de forma totalmente "impessoal e grosseira".

De fato, prevê-se que o período pós-pandemia trará consigo pressões para a generalização da Educação a Distância como se fosse equivalente ao ensino presencial. Aprofunda-se, assim, a tendência à conversão da educação em mercadoria na esteira da privatização que implica, sempre, a busca da redução dos custos visando o aumento dos lucros.

Deve-se ter presente que, pela sua própria natureza a educação só pode ser presencial. Como uma atividade da ordem da produção nãomaterial em que o produto não é separável do ato de produção, a educação se constitui, necessariamente, como uma relação interpessoal implicando, portanto, a presença simultânea dos dois agentes educativos: o 
professor com seus alunos. E sabe-se que uma das principais funções da educação é a socialização das crianças e jovens, o que não pode ser feito com o ensino remoto ou a distância e muito menos com o ensino dito doméstico.

Na verdade, a tecnologia, desde a origem do ser humano não é outra coisa senão extensão dos braços humanos visando a facilitar seu trabalho. E hoje, com o advento da automação, toda a humanidade poderia viver confortavelmente com poucas horas de trabalho diário liberando tempo disponível para o cultivo do espírito, abrindo-se para as formas estéticas, ou seja, para a apreciação das coisas e das pessoas pelo que elas são em si mesmas, sem outro objetivo senão o de relacionar-se com elas. O que impede a generalização desse estágio é a apropriação privada dos meios de produção fazendo com que, de meio de libertação dos indivíduos do trabalho pesado e de redução do tempo de trabalho socialmente necessário, a tecnologia se converta em instrumento de submissão da força de trabalho a um tempo sem limite conduzindo-a à exaustão. Foi isso o que aconteceu na Revolução Industrial com a introdução da maquinaria, o que levou os trabalhadores a destruir as máquinas. Mas as máquinas viriam a facilitar seu trabalho e, portanto, não eram suas inimigas. Seus inimigos eram os donos das máquinas que se serviam delas para impor um ritmo alucinante à atividade dos trabalhadores. É essa situação que se manifesta agora com as novas tecnologias expressando-se no fenômeno da uberização do trabalho.

Entendo que o mais sensato agora é simplesmente cancelar o calendário letivo de 2020. Não há a mínima possibilidade de retorno às aulas presenciais como está sendo programado, pois a pandemia se expande com uma média diária acima dos mil óbitos. Deve-se, então, desenvolver atividades de leitura e escrita para todos os alunos independentemente da série em que estariam matriculados caso não sobreviesse a pandemia como, aliás, já foi proposto pela nossa colega, a Professora Maria de Fátima Félix Rosar, do Maranhão, em uma live realizada em 9 de julho. Trata-se de prover as residências com as condições de sobrevivência mantendo a 
merenda escolar sendo entregue nas casas dos alunos, com os governos assegurando programas de renda para a manutenção das famílias, acesso à água tratada nas residências e produtos de higiene. Em seguida, prover o acesso à internet ao maior número possível de residências e fazer uma seleção de livros que seriam indicados para leitura digital nos casos em que isso estivesse disponível e distribuídos na forma impressa nos demais casos. E os alunos fariam, após a leitura, breves redações sobre o conteúdo dos livros lidos submetidas à avaliação dos professores. Assim, os alunos não deixariam de estudar, permaneceriam ativos desenvolvendo a capacidade de leitura e escrita que é necessária e útil à aprendizagem de todas as disciplinas dos currículos escolares. Dessa forma, ao serem retomadas as aulas presenciais a partir do ponto em que foram interrompidas em março de 2020, os alunos, tendo ampliado sua competência em leitura e escrita, estarão mais preparados para dar conta da programação das diversas disciplinas curriculares.

Enfim, cabe registrar que o Brasil perdeu uma grande oportunidade de se constituir em exemplo para todo o mundo no enfrentamento da pandemia. Tinha condições bastante favoráveis para esse protagonismo. Dispondo do SUS, o maior Sistema Universal de Saúde do planeta e sendo um dos últimos países a ser afetado, se beneficiava, também, do conhecimento das ações levadas a efeito pelos países que tiveram êxito como Nova Zelândia, Coréia do Sul, Alemanha, Vietnã e a própria China podendo, então, planejar o enfrentamento levando em conta essas experiências bem sucedidas. Mesmo com o sucateamento do SUS e a destruição do Programa "Mais Médicos", o governo federal deveria, assim que foi anunciada na China a manifestação do Corona vírus, reforçar o orçamento do suS repondo os bilhões que haviam sido subtraídos no processo de sucateamento e acrescentando recursos novos com a aprovação, pelo Congresso Nacional, do "estado de emergência" e coordenar o enfrentamento nacional à Covid 19 reequipando os hospitais e celebrando contratos de aquisição dos insumos necessários que, feitos em âmbito nacional, pela maior magnitude teriam melhores condições de vencer a 
concorrência a preços bem mais acessiveis. Com a omissão do governo federal, os governos estaduais e municipais tiveram de procurar adquirir de forma isolada submetendo-se a preços abusivos além de transtornos quanto à entrega dos equipamentos necessários. O governo federal sequer aplicou os recursos destinados ao combate da epidemia tendo se limitado a apenas $29 \%$ do montante aprovado pelo Congresso numa atitude que, mais do que irresponsável pode ser mesmo classificada como genocida, pois desperdiçou recursos aplicando-os de forma equivocada como foi o caso do Laboratório Químico e Farmacêutico do Exército que já gastou mais de R\$ 1,5 milhão para ampliar, em 100 vezes, sua produção de cloroquina, medicamento sabidamente ineficaz para o combate à Covid 19. Com o presidente da República agindo como aliado do vírus, o Brasil não só perdeu a oportunidade de ouro de confirmar sua competência reconhecida no enfrentamento anterior de epidemias; acabou se transformando no país que disputa com os Estados Unidos a pior posição no combate à pandemia.

\section{Sobre o desmonte da educação nacional na conjuntura do coronavírus e da crise política brasileira}

Levando em conta que o modo de produção capitalista tornou-se a forma dominante que se expandiu por toda a terra tendo atingido, em consequência, seu grau máximo de desenvolvimento; e que nesse contexto, as relações de produção baseadas na propriedade privada dos meios de produção, de impulso que eram, agora se transformaram em freios das forças produtivas abrindo-se uma época de revolução, podemos considerar que essa situação de crise global, de caráter estrutural, impacta fortemente a educação de várias maneiras as quais, no entanto, podem ser agrupadas em duas modalidades: a primeira corresponde à tendência que vem prevalecendo na qual a educação, de modo geral, e a escola em particular cada vez mais se vergam ante as imposições do mercado. A segunda tem sua possibilidade condicionada à reversão da primeira expectativa, o que implica a transformação radical, isto é, revolucionária da ordem atual. 
Assim, a primeira tendência para a qual caminha a educação, em geral, e a educação pública, em particular, é aquela que se realizará espontaneamente como que de acordo com o princípio da inércia. Diria que esta é uma tendência previsível e plenamente viável da educação na situação atual de crise estrutural do capitalismo.

Essa primeira tendência é aquela que está nas ruas, na mídia e se expressa diretamente na ação de grandes conglomerados econômicos que tomam a escola como objeto de investimento capitalista, assim como nas ações das organizações ditas não-governamentais ligadas a grandes grupos econômicos que, em alguns casos, convergem num movimento de maior envergadura como o "Todos pela Educação", manifestando-se também nas políticas educacionais nos níveis federal, estadual e municipal. Do ponto de vista das ideias pedagógicas essa tendência é representada pelo neoprodutivismo com as variantes do neo-escolanovismo, neoconstrutivismo e neotecnicismo que circulam na forma de supostas teorias travestidas de últimas novidades, na forma das tais "pedagogias do aprender a aprender" que aparecem em versões como "pedagogia da qualidade total", "pedagogia das competências", "pedagogias da inclusão", "pedagogia multicultural", "teoria do professor reflexivo", "pedagogia corporativa", "pedagogia social" e assemelhadas. Nesse quadro promove-se a fetichização das novas tecnologias com uma açodada adesão à educação a distância expandindo o processo de alienação das crianças e jovens. Penetrando nas escolas, as referidas "pedagogias" as descaracterizam convertendo-as em espaços anódinos, esvaziados da função própria da escola ligada ao objetivo de assegurar às novas gerações a apropriação dos conhecimentos sistematizados. É essa tendência que se desenha como hegemônica e que pode perdurar ainda por muitos anos e que, no Brasil, assume características extremas com o atual governo marcado pela destruição total dos poucos avanços que vínhamos alcançando.

Infelizmente, as instituições próprias da democracia, desde 2013, estão sendo cúmplices, por ação ou omissão, da erosão do Estado de Direito. De fato, no clima de ódio contra o PT incentivado pela insistência da mídia 
diariamente esmiuçando denúncias não comprovadas contra Dilma, Lula e o PT criou-se uma situação muito grave porque todas as instituições da República (Judiciário, Ministério Público, a própria Ordem dos Advogados do Brasil, as entidades empresariais à frente a FIESP com Paulo Skaf, Parlamento, Partidos políticos, toda a grande mídia televisiva, escrita e falada) foram conspurcadas e obcecadas com o objetivo de destruir o PT e impedir Lula de voltar a se candidatar. E, para isso, não têm tido pejo em violar os direitos mais elementares, desembocando no golpe jurídico-midiático-parlamentar desencadeado em 17 de abril na Câmara dos Deputados e consumado no Senado em 31 de agosto de 2016 que foi legitimado pela eleição de Bolsonaro, em 2018, num verdadeiro suicídio da democracia brasileira.

Tanto o Tribunal Superior Eleitoral como o Supremo Tribunal Federal tiveram diversas evidências das ilegalidades cometidas pela campanha de Bolsonaro e pela Lava Jato, mas não tomaram as medidas cabíveis. Conforme reportagem do Jornal Folha de S.Paulo de 18 de outubro de 2018, a campanha de Bolsonaro contratou empresas de disparos de mensagens em massa que, pelo WhatsApp, espalharam notícias falsas contra a candidatura do PT em flagrante violação do artigo 222 do Código Eleitoral Brasileiro que define como "anulável a votação, quando viciada de falsidade, fraude, coação...". Mas o Superior Tribunal Eleitoral nada fez diante dessa flagrante violação. E o STF vem sendo conivente com as evidentes ilegalidades denunciadas pela defesa de Lula não julgando os recursos e os "Habeas Corpus" e ignorando também as provas da "Intercept Brasil" publicadas em colaboração com outros órgãos de imprensa. Agora há a investigação das "fake News" no STF que, no entanto, está se arrastando e apenas se aproximando dos filhos de Bolsonaro deixando à margem o próprio Bolsonaro. Se o STF estivesse, de fato, cumprindo sua função como guardião da Constituição, poderia ter posto um basta a tudo isso já em 17 de abril de 2016 determinando a prisão em flagrante delito de Bolsonaro pelo crime de apologia à tortura quando, ao declarar seu voto, prestou homenagem a Brilhante Ustra classificado por ele como "o terror de Dilma Rousseff". Observe-se que se ele tivesse apenas homenageado Brilhante 
Ustra ele poderia se defender argumentando que não estava defendendo a tortura. Mas, ao qualificá-lo como "o terror de Dilma Rousseff ele aclamou a tortura, pois Brilhante Ustra comprovadamente torturou Dilma Rousseff. Portanto, naquele momento, Bolsonaro proclamou-se publicamente um apologista da tortura, crime que, conforme $\circ \S 6^{\circ}$ do Art. $1^{\circ}$ da Lei n 9.455 de 07 de Abril de 1997, "é inafiançável e insuscetível de graça ou anistia". Eis porque, após fazer aquele pronunciamento, ele deveria ser preso em flagrante delito. Também caberia ao STF abortar o processo contra Dilma diante do não cumprimento da exigência constitucional da existência de crime de responsabilidade, pois é para isso que a Constituição prevê que a sessão do Senado de deliberação sobre o impeachment seja presidida pelo Presidente do STF.

Nesse quadro de quebra da institucionalidade democrática abriu-se espaço para, mediante a disseminação das chamadas "Fake News" pelas redes sociais, chegar ao governo uma facção da extrema direita que vem provocando um enorme retrocesso econômico, social, político, cultural, sanitário e educacional em nosso país. Trata-se de um caso inédito de autorrecolonização do país, num verdadeiro crime de lesa-pátria.

Vejam! Estou me referindo à autorrecolonização do país, que se configura como um caso inédito. Com efeito, já se viu algum país que, tendo ficado independente da condição colonial, resolveu decidir, por sua própria iniciativa, voltar a ser colônia? E na verdade é isso que o atual governo está fazendo. Está abrindo mão da soberania do país, destruindo a indústria nacional, subvertendo as instituições e prestando reverência a uma potência externa, os Estados Unidos, subordinando-se aos desígnios e interesses dessa potência. Os países colonizados deram origem àquilo que depois passou a ser chamado de países subdesenvolvidos e nós, no estudo da geografia no antigo ginásio, aprendemos que país desenvolvido é aquele que importa matérias primas e exporta produtos manufaturados; e país subdesenvolvido é aquele que exporta matérias primas e importa produtos manufaturados. Embora comumente se entenda que país subdesenvolvido é aquele que se encontra num nível menor de desenvolvimento em relação aos países 
desenvolvidos, de fato subdesenvolvido significa desenvolvimento subordinado. Ou seja, um país subdesenvolvido é aquele cujo desenvolvimento encontra-se subordinado ao de outros países. Em suma, os países subdesenvolvidos são aqueles de economia predominantemente rural enquanto que os desenvolvidos são aqueles industrializados.

O Brasil passou por esse processo: a partir de uma economia de base agrícola centrada na monocultura do café, que era, no Império e na República Velha, o principal produto de exportação, desencadeou-se o processo de industrialização que foi acelerado pela crise do capitalismo mundial cujo epicentro foi a quebra da Bolsa de Nova lorque em 1929. Por meio dos recursos obtidos com a exportação do café eram importados os bens manufaturados. Com a crise mundial as exportações caíram e, com isso, as importações ficaram dificultadas seja porque os recursos disponíveis para financiar a aquisição dos bens manufaturas se reduziram, seja porque os países exportadores, igualmente em crise, também tiveram de reduzir sua produção. Nessas circunstâncias os capitais acumulados com as exportações do café foram deslocados para financiar o processo de industrialização com base no modelo de substituição das importações.

Foi dessa forma que ocorreu o processo de industrialização do Brasil que se desenrolou em duas fases: a primeira correspondeu à substituição dos bens de consumo não duráveis com destaque para as indústrias têxteis e alimentícias que, por serem de baixa relação produto-capital, não necessitavam de grandes somas de investimento para serem implantadas, o que permitiu seu desenvolvimento entre os anos de 1930 e 1950. A segunda fase compreendeu a substituição dos bens de consumo duráveis (automóveis, máquinas agrícolas e aparelhos eletrodomésticos) que, por serem de alta relação produto-capital, requeriam vultosos investimentos. Assim, para viabilizar sua implantação num prazo curto foram atraídas as grandes empresas estrangeiras multinacionais que se implantaram no Brasil no governo de Juscelino Kubitschek entre 1956 e 1960 consoante seu lema "Cinquenta anos em cinco" prometendo que durante seu mandato de cinco anos ele faria o país avançar cinquenta anos. Completou-se, assim, o ciclo 
da substituição das importações: já não dependíamos mais das manufaturas trazidas do exterior. A meta da industrialização havia sido atingida.

Mas após o golpe de 2016, legitimado pelas eleições de 2018, implantou-se no país um governo antipopular e antinacional que vem inviabilizando qualquer possibilidade de protagonismo do Brasil no cenário internacional. E, com a destruição de nosso parque industrial e a venda das empresas nacionais a preços vis, nós voltamos à condição de país subdesenvolvido que exporta matérias primas, agora chamadas de commodities, que o Dicionário Houaiss (2001, p. 771: verbete Commodity) assim conceitua:

\begin{abstract}
"qualquer bem em estado bruto, geralmente de origem agropecuária ou de extração mineral ou vegetal, produzido em larga escala mundial e com características físicas homogêneas, seja qual for a sua origem, geralmente destinado ao comércio externo"; e, numa outra acepção: "cada um dos produtos primários (p.ex., café, açúcar, soja, trigo, petróleo, ouro, diversos minérios etc.), cujo preço é determinado pela oferta e procura internacional".
\end{abstract}

É nesse contexto que vem ocorrendo o desmonte da educação nacional pelo corte dos recursos destinados à educação, à ciência e à pesquisa científica, pelo ataque à educação pública com ameaças e iniciativas efetivas de privatização e com a desqualificação e perseguição aos professores. De fato, como ele próprio afirmou, Bolsonaro veio não para construir, mas para destruir o país. No caso da educação, o projeto é destruir a educação pública submetendo todos os níveis e modalidades de ensino aos interesses privados convertendo a educação em mercadoria. E para isso vários mecanismos são aventados, além da privatização direta: terceirização, transferência da gestão para organizações sociais, Educação a Distância, convênios com entidades privadas, parcerias público-privadas, compra de pacotes preparados por entidades privadas, nomeação de representantes do ensino privado para integrar os órgãos públicos de normatização e avaliação da educação; e agora vem se cogitando até mesmo da adoção de vouchers. 
Quando candidato, Bolsonaro afirmava que iria compor os ministérios e demais cargos do governo federal priorizando a competência técnica e não as indicações políticas. Assumindo o governo, está agindo de forma exatamente oposta. As indicações seguem critérios político-ideológicos e se restringem ao círculo dos cúmplices primando pela inexperiência e incompetência dos indicados, o que se converteu em regra para todos os ministérios, mas se evidenciou de forma mais gritante no caso da Educação.

O primeiro que ocupou a pasta foi Velez Rodriguez que cometeu várias trapalhadas como chamar os brasileiros de canibais e conclamar os diretores a receber os alunos no início do ano letivo com a leitura de uma mensagem sua que terminava com o slogan de campanha do Bolsonaro: "Brasil acima de tudo, Deus acima de todos!". E determinava que "professores, alunos e demais funcionários da escola, com todos perfilados diante da bandeira nacional, fosse executado o hino nacional" e "que um representante da escola filmasse trechos curtos" da leitura e da reprodução do hino. Velez ficou pouco mais de três meses no governo e pelo menos voltou atrás e pediu desculpas.

Já Weintraub, que o sucedeu, ficou aproximadamente quinze meses, revelou-se um boquirroto, um obscurantista belicoso dizendo barbaridades sem jamais se desculpar. Sua gestão foi marcada por cortes de $30 \%$ no orçamento das universidades federais com acusações, obviamente falsas e genéricas, de baderna e plantações de maconha; pelo lançamento, em julho de 2019, do Programa "Future-se" visando, por meio de vários mecanismos, privatizar, em larga medida, o financiamento e a gestão da universidades e institutos federais; por protagonizar uma crise no ENEM 2019 com erros nas correções das provas; pela iniciativa de, por meio de decreto do presidente, chamar para si a atribuição de nomear, ao seu alvedrio, os reitores das universidades federais à revelia das eleições da comunidade universitária, o que, por ferir o preceito constitucional da autonomia universitária, foi vetado judicialmente; por baixar, imediatamente antes de deixar o ministério, portaria acabando com incentivo a cotas para negros, indígenas e pessoas com deficiência em cursos de pós-graduação, medida 
tão inusitada que o próprio ministério revogou logo após sua demissão. Assim, Weintraub acabou deixando o MEC e viajando intempestivamente para os Estados Unidos para escapar ao risco de ser preso, pois está sendo processado por ofensas ao STF.

Aquele que seria o terceiro ministro da educação em menos de 18 meses do mandato de Bolsonaro, Carlos Alberto Decotelli, foi nomeado em 25 de junho de 2020, mas renunciou cinco dias depois, em 30 de junho, antes de tomar posse oficialmente.

Em 16 de julho tomou posse Milton Ribeiro como o novo ministro da educação. Pastor presbiteriano e membro do Conselho Deliberativo da entidade mantenedora da Universidade Presbiteriana Mackenzie, obteve Doutorado em Educação na USP com a tese "CALVINISMO NO BRASIL E ORGANIZAÇÃO: o poder estruturador da educação". Parece, pois, ter algum espírito acadêmico, fato que alimentaria a esperança de um diálogo mais respeitoso com a comunidade universitária e com os profissionais da educação, o que ele prometeu no discurso de posse. No entanto, ele, além de aceitar o convite de Bolsonaro prometeu também, no mesmo discurso, que irá se empenhar em seguir a orientação do presidente. Assim, o que parece mais provável é que, detendo alguma competência técnica diferentemente de seus dois antecessores, poderá ter mais êxito na política de desmonte da educação já que, tanto Velez Rodriguez como Weintraub, em razão das sucessivas trapalhadas, diante da resistência enfrentada, não conseguiram avançar muito no processo de desmonte, que é a meta do governo Bolsonaro. Por enquanto, porém, passados 25 dias de sua posse, ainda não mostrou a que veio, sendo que assim que assumiu o ministério testou positivo para Covid 19, entrando em quarentena.

\section{Resistência ao desmonte e uma nova perspectiva para a educação nacional}

A outra tendência situa-se no âmbito contra hegemônico e corresponde à resistência à tendência dominante antes descrita, aliada aos esforços para introduzir, buscando generalizá-la, a escola unitária exigida 
pelo estágio atual atingido pelas forças produtivas. A proposta da escola unitária é construída sobre a base do conceito do trabalho como princípio educativo que compreende três significados: Num primeiro sentido, o trabalho é princípio educativo na medida em que determina, pelo grau de desenvolvimento social atingido historicamente, o modo de ser da educação em seu conjunto. Nesse sentido, aos modos de produção correspondem modos distintos de educar com uma correspondente forma dominante de educação. Em um segundo sentido, o trabalho é princípio educativo na medida em que coloca exigências específicas que o processo educativo deve preencher, em vista da participação direta dos membros da sociedade no trabalho socialmente produtivo. Finalmente, o trabalho é princípio educativo num terceiro sentido, à medida que determina a educação como modalidade específica e diferenciada de trabalho: o trabalho pedagógico.

Inspirado nas reflexões de Gramsci sobre o trabalho como princípio educativo da escola unitária, procurei delinear (SAVIANI, 2017, p. 55-59) a conformação do sistema de ensino tendo em vista as condições da sociedade brasileira atual. Conforme Gramsci, a escola unitária corresponde à fase que hoje, no Brasil, é definida como a educação básica, especificamente nos níveis fundamental e médio.

Considerando o primeiro sentido do trabalho como princípio educativo, vemos que o modo como está organizada a sociedade atual é a referência para a organização do ensino fundamental. O nível de desenvolvimento atingido pela sociedade contemporânea coloca a exigência de um acervo mínimo de conhecimentos sistemáticos sem o que não se pode ser cidadão, isto é, não se pode participar ativamente da vida da sociedade.

O acervo em referência inclui a linguagem escrita e a matemática, já incorporadas na vida da sociedade atual; as ciências naturais, cujos elementos básicos relativos ao conhecimento das leis que regem a natureza são necessários para se compreender as transformações operadas pela ação do homem sobre o meio ambiente; e as ciências sociais, pelas quais se 
pode compreender as relações entre os homens, as formas como eles se organizam, as instituições que criam e as regras de convivência que estabelecem, com a consequente definição de direitos e deveres. O último componente (ciências sociais) corresponde, na atual estrutura, aos conteúdos de história e geografia. Eis aí como se configura o currículo da escola elementar.

A base em que se assenta a estrutura do ensino fundamental é o princípio educativo do trabalho. O estudo das ciências naturais, assinala Gramsci, visa introduzir as crianças na "societas rerum" e pelas ciências sociais elas são introduzidas na "societas hominum":

O conceito e o fato do trabalho (da atividade teórico-prática) é o
princípio educativo imanente à escola elementar, já que a ordem
social e estatal (direitos e deveres) é introduzida e identificada
na ordem natural pelo trabalho. O conceito do equilíbrio entre
ordem social e ordem natural sobre o fundamento do trabalho,
da atividade teórico-prática do homem, cria os primeiros elementos
de uma intuição do mundo liberta de toda magia ou bruxaria, e
fornece o ponto de partida para o posterior desenvolvimento de
uma concepção histórico-dialética do mundo... (GRAMSCl, 1975, vol.
III, p. 154l; na edição brasileira, 1968, p. 130).

Uma vez que o princípio do trabalho é imanente à escola elementar, isto significa que no ensino fundamental a relação entre trabalho e educação é implícita e indireta. Ou seja, o trabalho orienta e determina o caráter do currículo escolar em função da incorporação dessas exigências na vida da sociedade. A escola elementar não precisa, então, fazer referência direta ao processo de trabalho, porque ela se constitui basicamente como um mecanismo, um instrumento, por meio do qual os integrantes da sociedade se apropriam daqueles elementos, também instrumentais, para a sua inserção efetiva na própria sociedade. Aprender a ler, escrever e contar e dominar os rudimentos das ciências naturais e das ciências sociais constituem pré-requisitos para compreender o mundo em que se vive, inclusive para entender a própria incorporação pelo trabalho dos conhecimentos científicos no âmbito da vida e da sociedade. 
Se no ensino fundamental a relação é implícita e indireta, no ensino médio a relação entre educação e trabalho, entre o conhecimento e a atividade prática deverá ser tratada de maneira explícita e direta. Intervém aqui, pois, o segundo sentido do conceito de trabalho como princípio educativo. O papel fundamental da escola de nível médio será, então, o de recuperar essa relação entre o conhecimento e a prática do trabalho.

Assim, no ensino médio já não basta dominar os elementos básicos e gerais do conhecimento que resultam e ao mesmo tempo contribuem para o processo de trabalho na sociedade. Trata-se, agora, de explicitar como o conhecimento (objeto específico do processo de ensino), isto é, como a ciência, potência espiritual, se converte em potência material no processo de produção. Tal explicitação envolve o domínio não apenas teórico, mas também prático sobre como o saber se articula com o processo produtivo.

O ensino médio envolverá, pois, o recurso às oficinas nas quais os alunos manipulam os processos práticos básicos da produção; mas não se trata de reproduzir na escola a especialização que ocorre no processo produtivo. O horizonte que deve nortear a organização do ensino médio é o de propiciar aos alunos o domínio dos fundamentos das técnicas diversificadas utilizadas na produção, e não o mero adestramento em técnicas produtivas. Não a formação de técnicos especializados, mas de politécnicos.

Politecnia significa, aqui, especialização como domínio dos fundamentos científicos das diferentes técnicas utilizadas na produção moderna. Nessa perspectiva a educação de nível médio tratará de se concentrar nas modalidades fundamentais que dão base à multiplicidade de processos e técnicas de produção existentes.

Esta é uma concepção radicalmente diferente da que propõe um ensino médio profissionalizante, caso em que a profissionalização é entendida como um adestramento em uma determinada habilidade sem o conhecimento dos fundamentos dessa habilidade e, menos ainda, da articulação dessa habilidade com o conjunto do processo produtivo. 
A concepção acima formulada implica a progressiva generalização do ensino médio como formação necessária para todos, independentemente do tipo de ocupação que cada um venha a exercer na sociedade. Sobre a base da relação explícita entre trabalho e educação se desenvolve, portanto, uma escola média de formação geral. Nesse sentido trata-se de uma escola de tipo "desinteressado" como propugnava Gramsci (1975, p. 486-487; na edição brasileira, 1968, p. 123-125) . É assim que ele entendia a escola ativa e não na forma como essa expressão aparecia no movimento da Escola Nova, isto é, a escola única diferenciada preconizada pela burguesia. E, para ele, o coroamento dessa escola ativa era a escola criativa, entendida como o momento em que os educandos atingiam a autonomia. Completava-se, dessa forma, o sentido gramsciano da escola mediante a qual os educandos passariam da anomia à autonomia pela mediação da heteronomia.

Finalmente, à educação superior cabe a tarefa de organizar a cultura superior como forma de possibilitar que participem plenamente da vida cultural, em sua manifestação mais elaborada, todos os membros da sociedade independentemente do tipo de atividade profissional a que se dediquem.

Assim, além do ensino superior destinado a formar profissionais de nível universitário (a imensa gama de profissionais liberais e de cientistas e tecnólogos de diferentes matizes), formula-se a exigência da organização da cultura superior com o objetivo de possibilitar a toda a população a difusão e discussão dos grandes problemas que afetam o homem contemporâneo. Terminada a formação comum propiciada pela educação básica, os jovens têm diante de si dois caminhos: a vinculação permanente ao processo produtivo através da ocupação profissional ou a especialização universitária.

Ora, em lugar de abandonar o desenvolvimento cultural dos trabalhadores a um processo difuso, trata-se de organizá-lo. É necessário, pois, que eles disponham de organizações culturais por meio das quais possam participar, em igualdade de condições com os estudantes 
universitários, da discussão, em nível superior, dos problemas que afetam toda a sociedade e, portanto, dizem respeito aos interesses de cada cidadão. Com isto, além de propiciar o clima estimulante imprescindível à continuidade do desenvolvimento cultural e da atividade intelectual dos trabalhadores, tal mecanismo funciona como um espaço de articulação entre os trabalhadores e os estudantes universitários, criando a atmosfera indispensável para vincular de forma indissociável o trabalho intelectual e o trabalho material.

Ressalte-se que essa proposta é bem diversa da atual função da extensão universitária. Não se trata de estender à população trabalhadora, enquanto receptora passiva, algo próprio da atividade universitária. Trata-se, antes, de evitar que os trabalhadores caiam na passividade intelectual, evitando-se ao mesmo tempo que os universitários caiam no academicismo. Aliás, Gramsci (1968, p.125-127) imaginava que tal função viesse a ser desempenhada exatamente pelas Academias que, para tanto, deveriam ser reorganizadas e totalmente revitalizadas deixando de ser os "cemitérios da cultura" a que estão reduzidas atualmente.

Por fim e com certeza o mais importante, deve-se considerar com toda a atenção e cuidado o problema do conteúdo da educação a ser desenvolvido no âmbito de todo o sistema. Está em causa, aqui, a questão do trabalho pedagógico em consonância com o terceiro sentido do conceito de trabalho como princípio educativo.

Conforme os documentos legais, a começar pela Constituição Federal e LDB, a educação tem por finalidade o pleno desenvolvimento da pessoa, o preparo para o exercício da cidadania e a qualificação para o trabalho. Levando-se em conta que esses objetivos se referem indistintamente a todos os membros da sociedade brasileira considerados individualmente, podemos interpretar, com Gramsci (1975, vol. III, p. 1547), que o objetivo da educação é conduzir cada indivíduo até a condição de ser capaz de dirigir e controlar quem dirige.

Fica claro que tal objetivo não poderá ser atingido com currículos que pretendam conferir competências para a realização das tarefas de certo 
modo mecânicas e corriqueiras demandadas pela estrutura ocupacional concentrando-se, e ainda de forma limitada, na questão da qualificação profissional e secundarizando o pleno desenvolvimento da pessoa e o preparo para o exercício da cidadania.

Diferentemente dessa tendência dominante, a organização curricular dos vários níveis e modalidades de ensino no âmbito do sistema nacional de educação deverá tomar como referência a forma de organização da sociedade atual, assegurando sua plena compreensão por parte de todos os educandos. Isso significa que se deve promover a abertura da caixa preta da chamada "sociedade do conhecimento". A educação a ser ministrada deverá garantir a todos o acesso aos fundamentos e pressupostos que tornaram possivel a revolução microeletrônica que está na base tanto dos mecanismos de automação que operam no processo produtivo como das tecnologias da informação que se movem nos ambientes virtuais da comunicação eletrônica.

Assim, além de tornar acessíveis os computadores pela disseminação dos aparelhos e em vez de lançar a educação na esfera dos cursos a distância de forma açodada, é preciso garantir não apenas o domínio técnico-operativo dessas tecnologias, mas a compreensão dos princípios científicos e dos processos que as tornaram possíveis. Se continuarmos pelos caminhos que estamos trilhando, não parece exagerado considerar que estamos, de fato, realizando aquelas profecias dos textos de ficção científica que previram uma humanidade submetida ao jugo de suas próprias criaturas, sendo dirigidas por máquinas engrenadas em processos automáticos. Pois não deixa de ser verdade que, cada vez mais, nos relacionamos com as máquinas eletrônicas, especificamente com os computadores considerando-os fetichisticamente como pessoas a cujos desígnios nós nos sujeitamos e, sem conseguirmos compreendê-los, atribuímos a eles determinadas características psicológicas traduzidas em expressões que os técnicos utilizam para nos explicar seu comportamento, tais como: ele, o computador, não reagiu bem ao seu procedimento; ele é assim mesmo, às vezes aceita o que você propõe e às vezes não aceita; etc. 
Nas condições atuais não é mais suficiente alertar contra os perigos da racionalidade técnica advogando-se uma formação centrada numa cultura de base humanística voltada para a filosofia, literatura, artes e ciências humanas à revelia do desenvolvimento das chamadas "ciências duras". É preciso operar um giro da formação na direção de uma cultura de base científica que articule, de forma unificada, num complexo compreensivo, as ciências humano-naturais que estão modificando profundamente as formas de vida passando-as pelo crivo da reflexão filosófica e da expressão artística e literária. É este o desafio que o sistema nacional de educação terá de enfrentar. Somente assim será possível, além de qualificar para o trabalho, promover igualmente o pleno desenvolvimento da pessoa e o preparo para o exercício da cidadania.

Enfim, pode-se afirmar que o trabalho foi, é e continuará sendo o princípio educativo do sistema de ensino em seu conjunto. Determinou o seu surgimento sobre a base da escola primária, o seu desenvolvimento e diversificação e tende a determinar sua unificação na luta pelo socialismo neste contexto de crise estrutural do capitalismo.

\section{Conclusão}

Ao encerrar, cumpre esclarecer que, para colocarmos em pauta a questão da escola unitária tal como sumariamente foi exposta no item anterior, precisamos resistir às tentativas de desmonte da educação nacional com a população se organizando e se mobilizando para reconstruir nossa democracia destruída quando ainda buscava se consolidar. Será uma luta longa e difícil porque democracia suicida significa precisamente isto: o povo iludido por falsas promessas, no exercício de sua soberania vota contra si mesmo elegendo seus próprios algozes. É uma luta árdua porque implica a mobilização contra cada medida antipovo e antinacional que vem sendo tomada pelo governo eleito articulando, ao mesmo tempo, essa mobilização com um trabalho educativo contínuo de conhecimento das condições objetivas como antídoto às ilusões ideológicas difundidas pela mídia tradicional e pelas redes sociais. É preciso, pois, uma forte mobilização 
conduzida pelos movimentos sociais populares e pelos sindicatos dos trabalhadores para reverter essa situação.

Mas o desenvolvimento da consciência social proletária como premissa para a ação política e ideológica eficaz implica dois aspectos que devem estar organicamente articulados entre si. Trata-se da educação, com destaque para a forma escolar, e a própria ação das massas organizadas.

A educação escolar é o meio mais adequado para a apropriação, pelos trabalhadores, das conquistas históricas da humanidade que lhes aguçarão a consciência da necessidade de intervir praticamente para dar continuidade ao processo histórico conduzindo-o a um novo patamar.

Além disso, é fundamental que as ações encetadas pelas organizações de massa dos trabalhadores se constituam em experiências da nova forma de sociedade quanto ao modo de organizar e de administrar as relações sociais. Isso é importante por produzir os germes da futura sociedade socialista e também porque seu êxito injeta um novo ânimo na luta dos trabalhadores dispondo-os a novas iniciativas, o que podemos constatar nas ações do MST. A forma resoluta com que seus militantes arregimentam rapidamente grande número de famílias para realizar ocupações e o modo como organizam e administram a vida nos acampamentos e assentamentos constituem gérmens da sociedade socialista que se quer implantar e, pelos resultados atingidos, revigoram suas forças e os animam a prosseguir na luta em busca de novas conquistas.

Sem essa luta política mais ampla não teremos como derrotar o golpe e implantar as medidas constitutivas de uma política educacional que venha assegurar a todos os brasileiros uma educação pública organizada segundo um alto padrão de qualidade aplicado a todos os níveis e modalidades de ensino com vigência em todo o território nacional.

Eis como os educadores devem se articular aos sindicatos de trabalhadores de todas as categorias profissionais e aos movimentos sociais populares nessa luta comum para resgatar o país das hostes do obscurantismo beligerante caminhando resolutamente para implantar uma nova forma de sociedade verdadeiramente livre e emancipada. 


\section{Referências}

GRAMSCl, Antonio. Os intelectuais e a organização da cultura. Rio de Janeiro: Civilização Brasileira, 1968.

GRAMSCl, Antonio. Quaderni del carcere. Torino: Einaudi, 1975.

HOUAISS, Antônio; VILLAR, Mauro de Salles. Dicionário Houaiss da Língua Portuguesa. Rio de Janeiro: Objetiva, 2001.

MÈSZÁROS, István. Para além do capital: rumo a uma teoria da transição. São Paulo: Boitempo, 2002.

SAVIANI, Dermeval. Educação e questões da atualidade. São Paulo: Livros do Tatu/Cortez, 1991.

SAVIANI, Dermeval. Sistema Nacional de Educação e Plano Nacional de Educação: significado, controvérsias e perspectivas, $2^{a}$ ed. revista e ampliada. Campinas: Autores Associados, 2017.

SHAIKH, Anwar "Crises econômicas". In: BOTTOMORE, Tom (Ed.). Dicionário do Pensamento Marxista. Rio de Janeiro: Jorge Zahar, 1988, p. 85-88.

Recebido em: 07 de julho de 2020 Aprovado em: 10 de agosto de 2020 Publicado em: 14 de agosto de 2020 